DOI 10. 18307/2022. 0209

(c) 2022 by Journal of Lake Sciences

\title{
水库环保疏浚及板框脱水工程中余水水质及变化规律
}

\author{
朱 伟 ${ }^{1}$, 许小格 ${ }^{1 * *}$, 侯 豪 $^{2}$, 程 林 $^{1}$, 李岳鸿 ${ }^{1}$,林小蔚 ${ }^{2}$, 吴 勇 $^{2}$ \\ (1: 河海大学环境学院, 南京 210098) \\ (2:河海大学土木与交通学院, 南京 210098)
}

\begin{abstract}
摘 要: 湖泊、水库、河流污染后实施底泥环保疏浚工程的实例很多,但如何处理疏浚余水以及处理尾水排放应该执行什 么样的控制标准, 是一个没有解决的问题. 针对这一问题, 本文以溧阳市沙河水库环保疏浚以及配套的泥浆板框压滤脱 水工程为例, 研究了余水发生后的水质以及在各处理环节中的变化规律, 基于这一规律探讨了疏浚尾水的排放标准. 结 果表明疏浚余水经过一级絮凝处理后大部分污染物可以去除, 悬浮物、总氮、总磷、COD 分别可去除 $73 \% \sim 99 \% 、 21 \%$ $72 \% 、 69 \%$ 96\%、32\% 48\%, 但后续的生态处理并没有体现出明显的效果. 通过处理后尾水基本上能够达到《污水综合 排放标准》(GB 8978-1996)一级排放标准,如需进一步提升排放标准,尾水中的氨氮成为制约性指标.
\end{abstract}

关键词: 环保疏浚;余水水质;板框压滤;尾水排放标准;尾水处理;沙河水库

\section{Water quality and change pattern of residual water in reservoir environmental dredging and plate and frame dewatering project*}

\author{
Zhu Wei ${ }^{1}$, Xu Xiaoge ${ }^{1 * *}, H_{0 u}$ Hao $^{2}$, Cheng Lin ${ }^{1}$, Li Yuehong ${ }^{1}$, Lin Xiaowei ${ }^{2} \&$ Wu Yong ${ }^{2}$ \\ (1: College of Environment, Hohai University, Nanjing 210098, P.R.China) \\ (2: College of Civil and Transportation Engineering, Hohai University, Nanjing 210098, P.R.China)
}

\begin{abstract}
There are many examples of environmental dredging applied on the polluted lakes, reservoirs, and rivers. However, the treatment of dredging residual water and the control standards of tailwater discharge have not been clearly defined yet. To address this issue, this paper takes the environmental dredging of the Shahe Reservoir and its supporting mud plate and frame filter press dewatering project in Liyang as an example, and studies the water quality after the occurrence of residual water and the changing pattern in each treatment process. Based on this pattern, the discharge standard of dredged tailwater is discussed. The results indicate that most of the pollutants in the dredged water can be removed after the first-level flocculation treatment. The removal rates of suspended solid, total nitrogen, total phosphorus and COD are $73 \%$ to $99 \%, 21 \%$ to $72 \%, 69 \%$ to $96 \%$ and $32 \%$ to $48 \%$ respectively, but the subsequent ecological treatment is not effective. Referring to the “Integrated Wastewater Discharge Standard” (GB 8978-1996), most of the treated tail water achieve the first level discharge standard. If the discharge standard needs to be further improved, the ammonia nitrogen in the tailwater would become a restrictive indicator.
\end{abstract}

Keywords: Environmental dredging; residual water quality; plate and frame filter; tail water discharge standard; tail water treatment; Shahe Reservoir

我国的多数湖泊、水库都存在着富营养化、有机物及重金属污染等水质问题,其中底泥作为内污染源向 上覆水体释放也会成为污染的原因之一 ${ }^{[1-2]}$. 在外源污染基本得到控制以后, 环保疏浚是清除湖泊内源污染 (主要是污染底泥) 的有效工程措施之一 ${ }^{[3]}$. 采用环保绞吸式挖泥船是目前较为常用的环保疏浚方法, 疏浚 泥浆在泥原的作用下直接通过管道被输送到陆地上的储泥场 (排泥场、堆场 ${ }^{[4]}$, 在储泥场内完成泥水分离 后进行后续处理. 由于环保绞吸式是将底泥变换成高含水率泥浆 ${ }^{[5]}$, 相对于底泥其体积会增量 $7 \sim 8$ 倍. 对

* 2021-06-23 收稿;2021-07-21 收修改稿.

江苏省科技计划项目 (BE2018737) 和中央高校专项项目 (B200204028) 联合资助.

** 通信作者;E-mail: xxg0626@163.com. 
于疏浚泥浆的处理, 由于储泥场土地确保的困难, 使用机械脱水并对脱水后的泥饼进行合理处置或资源化 利用变为目前较为常用的方法. 目前国内约 $60 \%$ 的疏浚泥浆采用直接堆放的方式处理,其余 $40 \%$ 则采用了 类似“泥浆浓缩 - 板框压滤 - 处置利用” 的处理工艺 ${ }^{[6]}$. 实际上在脱水过程中会产生底泥 7 8 倍体积的尾 水排放,大量尾水排放可能产生的二次污染以及环境负荷越来越受到关注 ${ }^{[3]}$.

目前, 疏浚余水的处理工艺大多采用物理法和化学法, 主要关注悬浮物 $(\mathrm{SS})$ 的去除, 并依托湖库河流等 疏浚工程进行研究和探讨. 霍守亮等 ${ }^{[7]}$ 针对五里湖疏浚堆场余水开展生产性试验研究, 通过延长水流路径 及向输泥管投加絮凝剂等措施促进颗粒物沉淀, 并发现余水中 SS 与总氮、总磷、COD 之间均存在很好的相 关性, 认为可以用 $\mathrm{SS}$ 作为余水排放的控制指标. 袁星等 ${ }^{[8]}$ 、刘志刚 ${ }^{[9]}$ 分别针对泉州市山美水库、滇池草海等 清淤工程的堆场余水, 采用物理、化学结合法对疏浚余水进行处理研究, 发现处理后尾水水质可达到《污水 综合排放标准》(GB 8978-1996)一级标准, 主要控制因子固体 SS 低于 $70 \mathrm{mg} / \mathrm{L}$. 王琦等 ${ }^{[10]}$ 、张志芳等 ${ }^{[11]}$ 则 采用物理、生物、化学综合处理方法分别对竺山湖和梅梁湖生态清淤的堆场余水进行处理, 疏浚余水依次通 过生物排泥池、沉淀池、澄清池, 最终余水排放水质达到《污水综合排放标准》( GB 8978-1996)二级标准, 主 要控制因子 SS 低于 $150 \mathrm{mg} / \mathrm{L}$. 何品晶等 ${ }^{[12]}$ 针对上海市杨浦区某河道经水力吸泥后离心脱水排出的上清液 (离心余水), 通过实验探索了澄清一砂滤一超滤组合工艺的净化效果, 结果表明依次加人 PAC 和 PAM ( 聚丙 烯酰胺) 的双调理混凝能有效沉降颗粒物, 旋流澄清尾水经砂滤可达污水排放二级标准, 再经超滤可达生活 杂用水的回用水质要求. 从这些研究现状来看, 针对目前较多采用的板框压滤系统的余水性质和处理效果 的研究较为缺乏. 另一方面, 我国目前对于疏浚余水的排放还没有相关标准, 虽然这些研究大多数参照了 《污水综合排放标准》( GB 8978-1996) 一级和二级标准, 但有些涉及到重要水体、饮用水水源地时往往需要 更高的标准进行控制. 那么通过环保疏浚、板框压滤所产生的余水性质到底是怎样的? 余水经过处理后能 达到怎样的水质标准? 余水排放应该执行什么样的标准? 都是工程界急需明确的问题.

本文结合溧阳市天目湖水源地 (沙河水库) 环保疏浚及泥浆板框压滤脱水工程 (以下简称沙河水库疏 浚一脱水工程), 在工程施工期对余水处理的不同工艺阶段进行了持续的水质监测. 沙河水库疏浚一脱水工 程的余水排区处于太湖流域上游, 并涉及到重要监测断面水质达标问题, 因此余水处理在常规物理法、化学 法 ${ }^{[13-14]}$ 的基础上,增加了“好氧塘+表流湿地”系统, 形成了“自然沉淀一混凝沉淀一生物曝气一表流湿地”处 理工艺. 本文以此工程为例, 对余水处理各处理塘的进水和出水取样分析, 研究该工艺各处理环节中余水的 物理、化学性质变化规律, 并在此基础上分析讨论了这套余水处理工艺中存在的问题, 探讨了余水处理系统 的净化能力及尾水排放水质标准,提出了合理的改进建议,以期为后续同类工程提供借鉴参考.

\section{1 研究对象与方法}

\section{1 工程概况}

沙河水库是太湖流域 7 座大型水库之一, 位于长三角平原与苏皖浙山区接合部、江苏省溧阳市城南约 $12 \mathrm{~km}$ 的天目湖镇境内、戴溪河干流一沙河上, 水域面积 $11.6 \mathrm{~km}^{2}$, 集水面积 $148.5 \mathrm{~km}^{2}$, 正常蓄水位 $21.00 \mathrm{~m}$, 相应库容 5970 万 $\mathrm{m}^{3}$. 水库始建于 1958 年 9 月, 是一座集防洪、灌溉、旅游、供水、发电、养殖等多种功能的国 家级大型水库 (II 型). 水库北部湖区底泥有机物与重金属复合污染严重, 造成饮用水安全形势十分严峻, 综 合考虑需要对沙河水库进行生态清淤. 根据沙河水库水下地形、地质和污染物分布情况, 确定疏浚范围为坝 前北部湖区, 疏浚总面积 63.60 万 $\mathrm{m}^{2}$, 疏浚厚度 $0.6 \sim 0.9 \mathrm{~m}$, 疏浚总量 50.00 万 $\mathrm{m}^{3}$ (含允许超挖量). 根据疏浚 时水下施工深度、工期及避免二次污染等条件要求, 选用了 1 台 $200 \mathrm{~m}^{3} / \mathrm{h}$ 深水型环保绞吸式挖泥船对水库 进行疏浚. 库底淤泥经绞吸式疏浚后变成了体积㝾者大、浓度极低的稀泥浆,伴随产生的是大量余水. 沙河水 库疏浚余水处理采用“自然沉淀一混凝沉淀一生物曝气一表流湿地”工艺,工艺简图如图 1.

疏浚泥浆首先经深水挖泥船加压后通过全封闭管道进人 $1^{\#}$ 池 ( 自然沉淀池, 规模: 围堰全长 $453 \mathrm{~m}$, 池深 $5 \mathrm{~m}$, 有效容积 $30000 \mathrm{~m}^{3}$, 图 1a), 绝大部分淤泥在此沉淀池中沉淀而后形成较高浓度泥浆, 当泥浆浓度达到 一定数值后, 位于池中的小挖泥船将高浓度泥浆输送到均化池中摚拌进而通过 2 台过滤面积 $800 \mathrm{~m}^{2} /$ 台的 板框压滤机将泥浆压成泥饼, 在均化池中掺加石灰作为助滤剂以加快过滤效率, 压滤尾水重新再进人 $1^{\#}$ 池. 最终压滤成的泥饼运至 $6 \mathrm{~km}$ 以外的矿坑进行处置利用. 在 $1^{\#}$ 池闸板箱体调节排水水位处添加 PAC( 聚合氯 
(a)

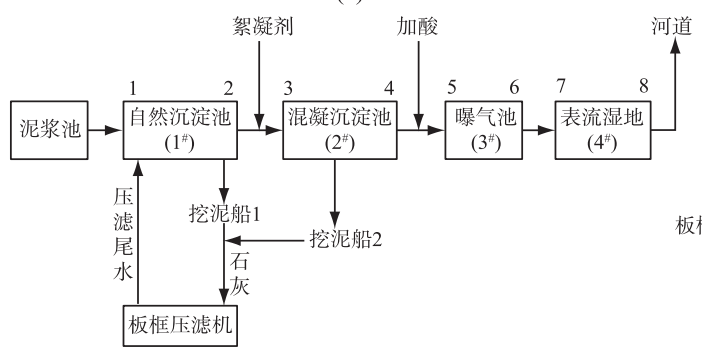

(b)

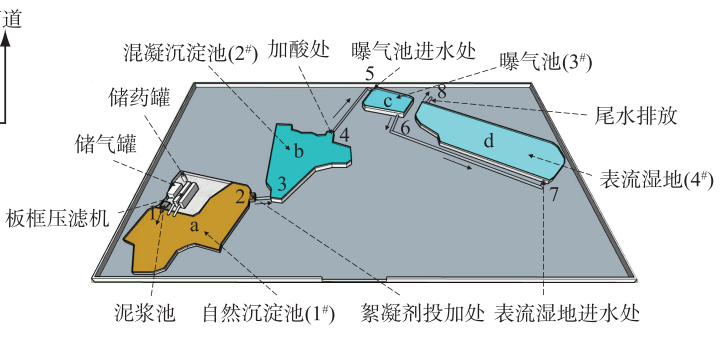

图 1 “自然沉淀一混凝沉淀一生物曝气一表流湿地”工艺示意图

$\left(1: 1^{\#}\right.$ 进水, $2: 1^{\#}$ 出水, $3: 2^{\#}$ 进水, $4: 2^{\#}$ 出水, $5: 3^{\#}$ 进水, $6: 3^{\#}$ 出水, $7: 4^{\#}$ 进水, $8: 4^{\#}$ 出水 $)$

Fig.1 Schematic diagram of "natural precipitation and coagulation precipitation and biological aeration and surface wetlands" process

化铝) 和 PAM ( 聚丙烯酰胺), 通过 $1^{\#}$ 池和 $2^{\#}$ 池 (混凝沉淀池, 规模: 围堰全长 $462 \mathrm{~m}$, 池深 $3.5 \mathrm{~m}$, 有效容积 $30000 \mathrm{~m}^{3}$, 图 $1 \mathrm{~b}$ ) 之间的管道进行充分混合, 通过 2 种絮凝剂促使上覆水中未沉淀的细小颗粒在 $2^{\#}$ 池中絮 凝沉淀, 降低上覆水中各种污染物含量, 当淤泥淤积到一定浓度后再次被输送到均化池而后进行压滤. 在 $2^{\#}$ 池出口处添加浓硫酸以调节上覆水 $\mathrm{pH} .3^{\#}$ 池 (生物曝气池, 规模: 面积 $4000 \mathrm{~m}^{2}$, 有效水深 $2.5 \mathrm{~m}$, 图 $1 \mathrm{c}$ ) 主要 分为两个模块: 曝气与填料. 全池通过曝气机进行曝气, 使水中氧气保持较高的浓度以促进微生物的生长繁 殖, 填料给微生物提供着床, 微生物不断进行新陈代谢来消耗水中的总氮 ( TN)、总磷 ( TP). $4^{\#}$ 池 (表流湿地 系统, 规模: 面积 $20000 \mathrm{~m}^{2}$, 图 1d) 池内种植芦苇和荷花, 运用植物根系以及根系上、根杆上附着的微生物群 落来吸收水中的有机物, 起到脱氮除磷的作用, 同时设置隔板使水流流径延长, 更利于水中微颗粒的降解最 终被水生植物吸收,最终尾水排人附近河道.

\section{2 样品采集与分析方法}

如图 1 所示, 为探究疏浚泥浆处理系统各环节对于余水的污染物去除效果, 于 2020 年 11 月- 2021 年 1 月, 对泥浆处理厂的压滤尾水和 4 个处理塘的进水、出水进行逐月采集, 每月 2 次. 样品均使用 $500 \mathrm{~mL}$ 聚乙 烯瓶保存, 低温运回实验室, 其中 $1^{\#}$ 池进水 (疏浚泥浆) 静置沉淀 $24 \mathrm{~h}$ 后取上覆水进行分析, 其他样品立即 进行分析. 此外, 在疏浚前还采集了水库 9 个点位的上覆水和相应的底泥柱状样品, 柱状样按照每 $20 \mathrm{~cm}$ 进 行分层,密封于聚乙烯袋中低温运回实验室进行分析.

各水质指标的监测分析方法参考《水和废水监测分析方法》 (第四版 $)^{[15]}$ 中相关规定方法进行, 其中 $\mathrm{pH}$ 使用 SX836 便携式 $\mathrm{pH}$ 仪进行现场测定, 浊度使用 SGZ-200AS 浊度计进行测定, TN 浓度采用碱性过硫酸钾 消解紫外分光光度法测定, TP 浓度以锄锑抗分光光度法进行测定, 氨氮 $\left(\mathrm{NH}_{3}-\mathrm{N}\right)$ 浓度采用纳氏试剂分光光 度法测定, 化学需氧量 (COD) 采用酸性高锰酸钾滴定法 (下文不再特别标出, 统称为 COD) 浓度. 底泥中有 机质 (OM) 的测定采用 ASTM D2974-00 的方法 ${ }^{[16]}$, 以烧失重 ( LOI) 表示, 即将烘干的底泥于 $550^{\circ} \mathrm{C}$ 下灼烧 5 $\mathrm{h}$, 计算灼烧后前后损失的质量与原底泥质量的比值, TN 含量测定方法为碱性过硫酸钾消解紫外分光光度 法,TP 含量采用酸熔一钿锑抗分光光度法.

\section{2 结果与分析}

\section{1 疏浚及疏浚泥处理过程中污染物的去向分析}

为了解在环保绞吸式疏浚过程中底泥中污染物向疏浚余水中的转化情况, 测定了疏浚前沙河水库底泥 中的 TN 、TP 和有机质含量, 上覆水以及疏浚后泥浆中的 TN 、 TP 浓度和 COD. 如图 2 所示, 疏浚前水库底泥 中 TN 含量均值约为 $863.48 \mathrm{mg} / \mathrm{kg}$, 上覆水 TN 浓度为 $0.72 \mathrm{mg} / \mathrm{L}$, 经由水下混合后变成浓度约为 $10 \%$ 的稀泥 浆, TN 浓度增加为原始上覆水的 5 倍, 分析是因为疏浚过程中污染底泥和水发生剧烈搅动, 一方面吸附有 氮、磷、有机物的细小颗粒大量进人余水中, 另一方面存在于底泥间隙水中的溶解态污染物也进人了余水. $\mathrm{TP}$ 与 $\mathrm{TN}$ 有相似的变化趋势, 但比 $\mathrm{TN}$ 增加幅度更大, 疏浚泥浆中 TP 浓度为原始上覆水的 11 倍, 而对比底 
泥中两者的含量, 发现 TP 仅为 $431.81 \mathrm{mg} / \mathrm{kg}$, 是 TN 含量的 $1 / 2$, 说明底泥中的磷比氮更易吸附在细颗粒上, 从而随着疏浚过程进人余水中.

疏浚后泥浆 COD 相比原始上覆水有所增加,但与 TN 、 TP 相比增幅不大, 仅为原来的 1.6 倍. 不同的河 流湖库, 因其底泥污染程度、原始上覆水水质以及疏浚方式的差异, 疏浚泥浆中 COD 也有所不同,一般在 $15 \sim 489 \mathrm{mg} / \mathrm{L}$ 左右 ${ }^{[9,17]}$. 根据对沙河水库的调查, 全库底泥有机质含量范围为 $1.67 \% \sim 6.10 \%$, 清淤范围内的 有机质含量相对偏高, 为 $2.86 \% \sim 6.10 \%$, 平均值为 $5.13 \%$, 与一般黑臭河道的底泥相比, 有机质污染相对较 轻, 因此进人疏浚泥浆中的有机物质含量相对较低, 疏浚泥浆 COD 平均值为 $4.17 \mathrm{mg} / \mathrm{L}$.

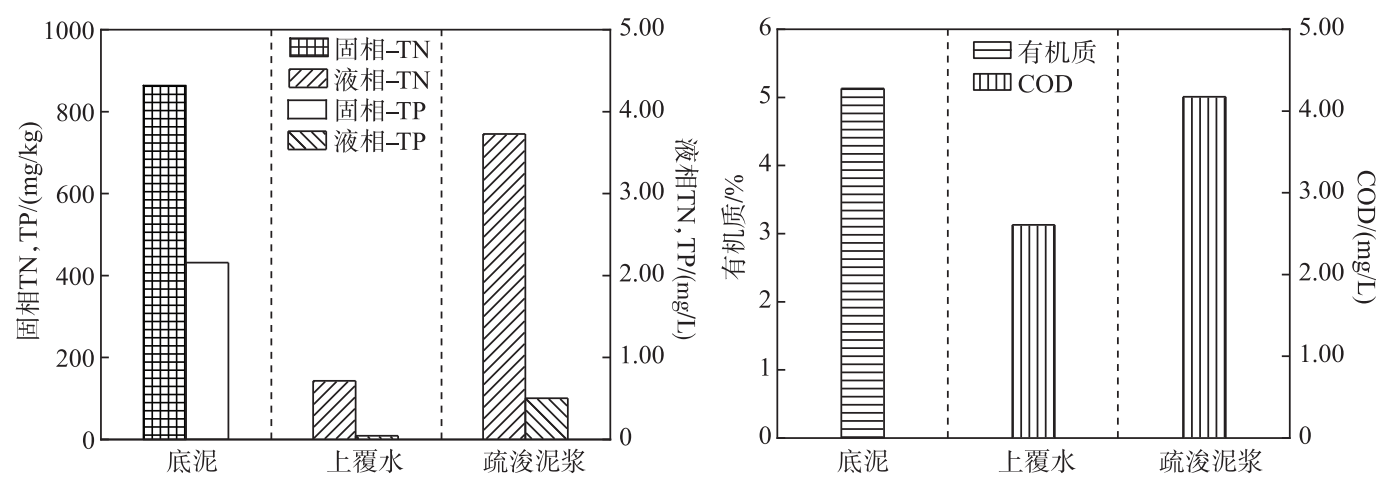

图 2 疏浚前后固一液中总氮、总磷、有机物质含量转化

Fig.2 Conversion of total nitrogen, total phosphorus and organic matter content in solid-liquid before and after dredging

\section{2 余水处理过程中的水质变化}

2020 年 11 月 -2021 年 1 月各处理塘进出水 TN 浓度变化的逐月监测情况可以看出, 总体上 TN 在经过 处理后浓度明显降低, 但随着不同的施工时期, 部分月份出现波动. 经过 $1^{\#}$ 池自然沉淀后, 上清液中 TN 浓度 呈现下降趋势, 同时可以发现浊度在这个过程中变化与之相似, 因此可以推测大部分的含氮污染物附着在 易于沉降的颗粒物上, 能够随着颗粒沉降而去除. 在 $1^{\#}$ 池出口处添加 PAC 和 PAM, 使悬浮颗粒进一步在 $2^{\text {\# }}$ 池混凝沉淀, 经过 2 个处理塘的自然沉淀和强化沉淀作用, $2^{\#}$ 池出水 TN 可达去除总量的 $84 \% \sim 100 \%$, 浓度 基本在 $1.5 \sim 2.5 \mathrm{mg} / \mathrm{L}$ 左右, 平均水质为地表 $\mathrm{V}$ 类水 (图 3a). $3^{*}$ 池和 $4^{*}$ 池对于 $\mathrm{TN}$ 的去除作用已经微乎其微, 可以看出后期 TN 基本不再发生变化, 分析原因一方面可能是 $3^{*}$ 池进水 $\mathrm{TN}$ 浓度已经较低, 后续生物作用的 效果难以体现出来, 另一方面秋、冬季节, 植物逐渐开始衰亡, 对营养盐的利用大大减弱, 同时植物体的死亡 分解也会向水体释放氮、磷 ${ }^{[18]}$.

与 $\mathrm{TN}$ 相反, 氨氮在经过处理后则均呈现出浓度显著升高的现象, 出水氨氮浓度可达进水的 $101 \%$ $318 \%$, 且主要增加区段在 $1^{\#}$ 池进水 $-2^{\#}$ 池进水之间, 后续处理过程中则基本保持稳定 (图 $3 \mathrm{~b}$ ). 根据吴思麟 等 ${ }^{[19]}$ 的研究, 在板框压滤过程中原本赋存于泥中的含氮污染物会随着压滤尾水被带出, 尾水中 TN 浓度相 当高, 多次的监测结果也显示, 压滤尾水中氨氮浓度一般在 7.35 9.21 mg/L 之间, 占 $\mathrm{TN}$ 的 $51 \% \sim 86 \%$, 而 $1^{\text {\# }}$ 池中原始上覆水氨氮浓度仅为 $0.35 \sim 1.68 \mathrm{mg} / \mathrm{L}$, 占 $\mathrm{TN}$ 的 $10 \% \sim 20 \%$, 因此高氮浓度的压滤尾水排人 $1^{\#}$ 池不 仅使上清液中 TN 浓度发生了很大的改变, 也造成了氨氮比例的显著变化, 对比 $1^{\#}$ 池处理后 $\mathrm{TN}$ 的下降趋势 (12 月份异常波动), 说明自然沉淀过程主要针对硝态氮的去除, 对于氨氮的去除作用不大. $2^{\#}$ 池进水氨氮浓 度较 $1^{\#}$ 池出水有所升高, 这可能是因为絮凝剂 PAM 本身带有氮元素, 向水体投加之后, 其对于氨氮的去除 作用短时间内还未发挥, 但其本身氮浓度已经对水质产生影响, 因此导致水中氨氮浓度升高. 经过 $2^{\#}$ 池处理 后, 出水氨氮下降 $9 \% \sim 27 \%$, 说明混凝沉淀对氨氮的去除有一定作用, 但作用不大. $3^{*}$ 池和 $4^{\#}$ 池则基本不发 挥作用.

疏浚余水经过 $1^{\#}$ 池自然沉淀后, TP 去除率为 $15 \% \sim 92 \%$ (图 4a). $1^{\#}$ 池进水 TP 浓度为 $0.15 \sim 1.32 \mathrm{mg} / \mathrm{L}$, 最高值和最低值相差近十倍, 但出水 TP 浓度并无明显差异, 基本都维持在 $0.11 \mathrm{mg} / \mathrm{L}$ 左右, 说明难以自然沉 

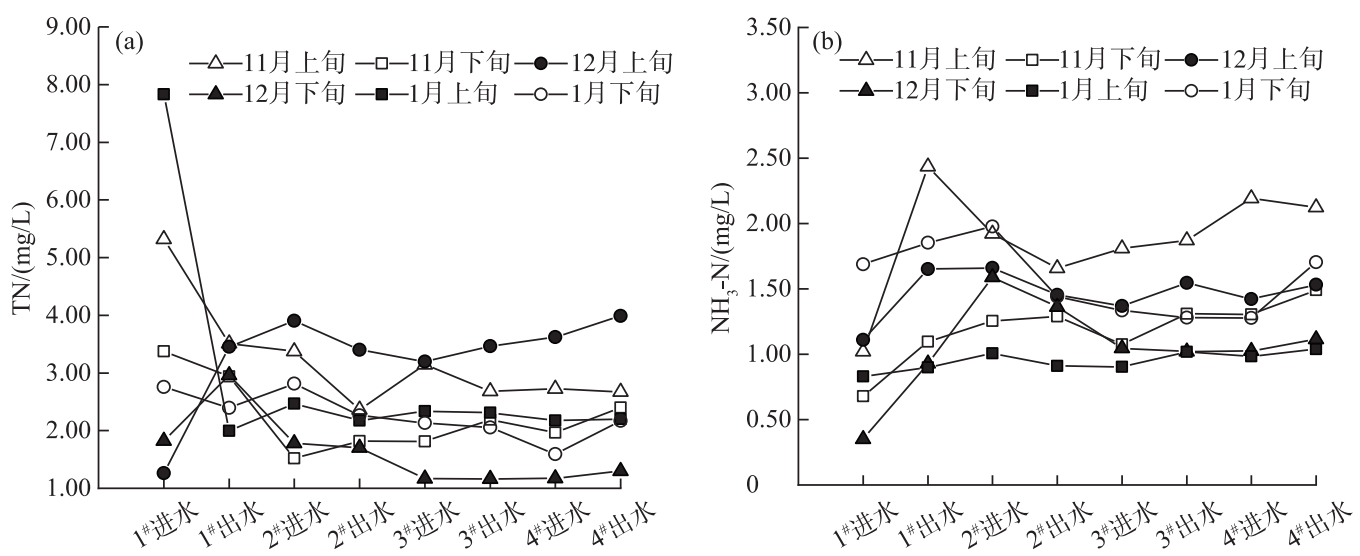

图 3 余水处理过程中 $\mathrm{TN}(\mathrm{a})$ 和 $\mathrm{NH}_{3}-\mathrm{N}(\mathrm{b})$ 浓度变化

Fig.3 Changes of $\mathrm{TN}(\mathrm{a})$ and $\mathrm{NH}_{3}-\mathrm{N}(\mathrm{b})$ concentration during residual water treatment

淀的细小颗粒物含量是相对稳定的. 絮凝剂投加后, 在 $1^{\#}$ 池和 $2^{\#}$ 池之间的管道充分混合, 同时对 TP 进一步 去除, $2^{\#}$ 池进水处 TP 去除率已达 $86 \%$ 97\%, 浓度基本在 $0.05 \mathrm{mg} / \mathrm{L}$ 以下, 说明余水中大部分的含磷污染物 为颗粒态,随着颗粒沉降被去除. 除 11 月份 2 次监测趋势不同外,其他月份变化总体一致,经过 $2^{\#}$ 池 TP 浓 度基本不发生改变, 说明混凝沉淀在连接 $1^{\#}$ 池和 $2^{\#}$ 池的管道中已经完成, 絮凝剂作用发挥迅速. $3^{\#}$ 池出口处 $\mathrm{TP}$ 浓度又有所回升, 可能是因为曝气引起的水体扰动使细小颗粒物重新悬浮, 在之后 TP 浓度又明显降低, $4^{\#}$ 池出水 TP 浓度和 $2^{\#}$ 池进水相差不大, 说明通过自然沉淀和混凝沉淀作用后, 余水中剩余 TP 已经很难进 一步去除, 且出水 TP 浓度与原始进水 TP 浓度之间无明显相关性, 最终均维持在 $0.01 \sim 0.06 \mathrm{mg} / \mathrm{L}$ 范围内.

从图 $4 \mathrm{~b}$ 可以看出, $\mathrm{COD}$ 在处理的整个流程中波动较大, 经过 $1^{\#}$ 池和 $2^{\#}$ 池沉淀作用后, $\mathrm{COD}$ 整体呈下降 趋势, 去除率为 $32 \% \sim 48 \%$. 经过 $3^{\#}$ 池和 $4^{\#}$ 池对 COD 的去除效果不明显, 且多数月份中, $4^{\#}$ 池出水浓度较进 水浓度反而有所升高, 这可能是因为秋冬季节, 植物体逐渐衰亡, 其分解的残体碎屑进人水体使出水 COD 升 高. 11 月份, 12 月下旬和 1 月下旬出水 $\mathrm{COD}$ 维持在 $3 \mathrm{mg} / \mathrm{L}$ 左右, 12 月上旬和 1 月上旬则表现出处理后出 水 $\mathrm{COD}$ 浓度高于进水的现象, 出水 $\mathrm{COD}$ 在 $5.5 \mathrm{mg} / \mathrm{L}$ 左右.
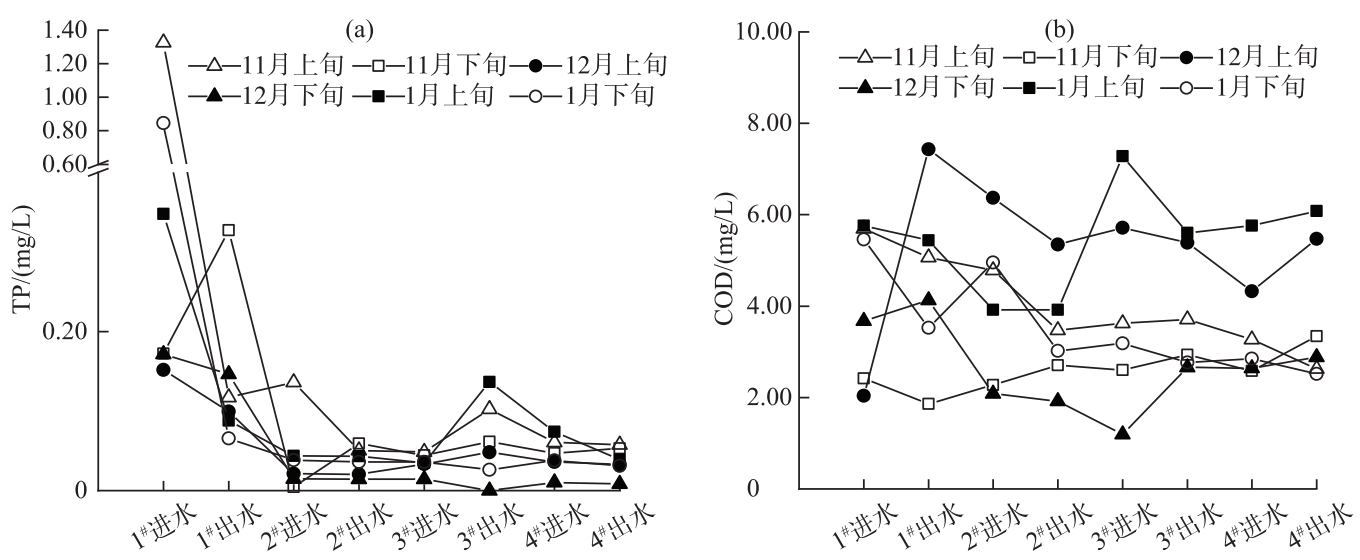

图 4 余水处理过程中 $\mathrm{TP}(\mathrm{a})$ 和 COD $(\mathrm{b})$ 浓度变化

Fig.4 Changes of TP (a) and COD (b) concentration during residual water treatment

从图 $5 \mathrm{a}$ 可以看出, 11 月下旬、 12 月下旬 $\mathrm{pH}$ 在处理过程中基本不发生变化,为偏碱性状态, 其他月份 $\mathrm{pH}$ 均表现出在 $1^{\#}$ 池出口处显著升高, $2^{\#}$ 池基本保持稳定, $3^{\#}$ 池进口处又大幅下降, 后续基本平稳的趋势, 分 
析出现该变化规律的原因是石灰的加人使得板框压滤尾水呈现强碱性, 压滤尾水排人 $1^{\#}$ 池, 与上清液混合 后, 导致 $1^{\#}$ 池出水 $\mathrm{pH}$ 明显升高, 在 $2^{\#}$ 池出口处加酸调节, 因此 $3^{\#}$ 池进水 $\mathrm{pH}$ 又出现显著下降, 最终出水 $\mathrm{pH}$ 在 7 9 之间, 呈微碱性. 而 11 月下旬和 12 月下旬的 $\mathrm{pH}$ 在 $1^{\#}$ 池出水至 $3^{\#}$ 池进水阶段与其他月份差异明显, 主要是由于来水水量等因素的变化使得 $1^{\#}$ 池出水 $\mathrm{pH}$ 并未显著升高, 满足出水水质对于 $\mathrm{pH}$ 的要求, 因此在 后续处理过程中省略了加酸调节这一步骤, 出现了整体较为平稳的趋势, 最终 $\mathrm{pH}$ 仍维持在 7 9 之间.

浊度虽然在个别段出现上升下落的波动现象, 但整体上为下降趋势, 经过 $1^{\#}$ 池和 $2^{\#}$ 池的沉淀作用, 浊度 降低效果显著,颗粒物去除可达 80\% 99\% (图 5b). 前期后续处理塘对浊度降低并无明显作用,后期为改善 处理效果, 在 $4^{\#}$ 池内设置隔板, 延长水流路径,并在出口前方增加陶粒滤料层, 可以看出 1 月份的 2 次监测 中, 经过 4 池浊度都有大幅下降, 去除率达 $56 \% \sim 91 \%$, 出水浊度均在 $40 \mathrm{NTU}$ 以下, 其中多次在 $0 \sim 5 \mathrm{NTU}$ 之间.
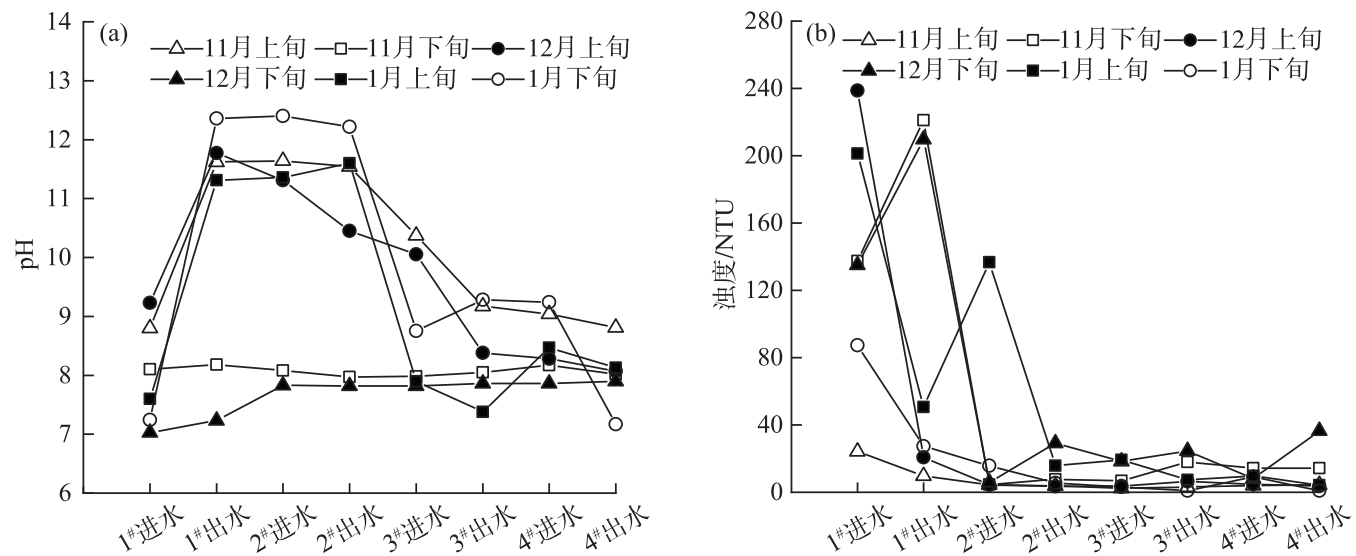

图 5 余水处理过程中 $\mathrm{pH}(\mathrm{a})$ 和浊度 $(\mathrm{b})$ 变化

Fig.5 Changes of $\mathrm{pH}$ ( a ) and turbidity (b) during residual water treatment

\section{3 影响余水处理的关键水质参数}

表 1 为余水处理过程中不同月份水中污染物浓度与浊度的关系. 浊度单位选取散射浊度单位 (NTU). 由表可知, TP 浓度与浊度呈极显著相关 $(P<0.01)$, TN 除 12 月上旬趋势异常之外, 其他月份与浊度也表现 出了较好的相关关系, 而氨氮与浊度的相关性则较差, 这与霍守亮等 ${ }^{[7]}$ 的研究结果一致,所不同的是, 霍守 亮等的研究中浊度与 COD 显著相关, 而本文两者关系不明确, 原因可能是 $4^{\#}$ 池表流湿地植物净化作用受季 节影响较大, 秋冬季一方面植物吸收作用下降, 另一方面植物体死亡分解碎屑进人水中, 导致出水 COD 不稳 定. 因此,通过控制余水中悬浮物浓度基本可控制 TN、TP 浓度,但无法保证出水氨氮及 COD.

表 1 浊度与各处理塘进出水水质的相关关系

Tab.1 Correlation between turbidity and the water quality of influent and effluent of each treatment pond

\begin{tabular}{ccccccc}
\hline Pearson 相关系数 & 11 月上旬 & 11 月下旬 & 12 月上旬 & 12 月下旬 & 1 月上旬 & 1 月下旬 \\
\hline 浊度 $-\mathrm{TP}$ & $0.961^{* *}$ & $0.982^{* *}$ & $0.875^{* *}$ & $0.917^{* * *}$ & $0.715^{*}$ & $0.963^{* * *}$ \\
浊度 $-\mathrm{TN}$ & $0.934^{* *}$ & $0.822^{*}$ & $-0.953^{* *}$ & $0.862^{* *}$ & $0.819^{*}$ & 0.591 \\
浊度 $-\mathrm{NH}_{3}-\mathrm{N}$ & -0.641 & -0.588 & $-0.790^{*}$ & -0.586 & -0.497 & 0.366 \\
浊度- $\mathrm{COD}$ & $0.759^{*}$ & -0.672 & $-0.792^{*}$ & $0.832^{*}$ & -0.242 & $0.809^{*}$ \\
\hline
\end{tabular}

*表示差异显著, $P<0.05 ; * *$ 表示差异极显著, $P<0.01$.

从处理流程各环节水质连续变化的角度来看, 沙河水库疏浚余水处理系统对 TN、TP、浊度的去除都发 挥了极大作用, 对 COD 的去除效果次之, 而对氨氮则无明显作用. 相比于原始的疏浚泥浆, 经处理后余水中 $\mathrm{TN}$ 浓度降低了 $21 \%$ 72\%, TP 浓度降低了 $69 \%$ ～96\% , 浊度降低了 73\% 99\%, 但氨氮浓度却增加了 $25 \%$ 
$218 \%$, 因此氨氮成为余水水质的关键限制性因素, 如何强化对氨氮的去除以及在去除浊度的同时如何控制 氨氮的增加是余水处理面临的关键问题.

\section{3 讨论}

\section{1 通过环保疏浚、板框压滤所产生的余水性质}

表 2 沙河水库疏浚原水及压滤尾水中 各类污染物浓度

Tab. 2 Concentration of various pollutants in dredging water and pressure filter tail water of Shahe Reservoir

\begin{tabular}{crrr}
\hline \multirow{2}{*}{ 指标 } & \multicolumn{2}{c}{ 疏浚原水 } & \multirow{2}{*}{ 压滤 } \\
\cline { 2 - 3 } & \multicolumn{1}{c}{ 范围 } & 平均值 & 尾水 \\
\hline 浊度 $/ \mathrm{NTU}$ & $24.2 \sim 238.8$ & 137.4 & 10.0 \\
$\mathrm{TN} /(\mathrm{mg} / \mathrm{L})$ & $1.26 \sim 7.83$ & 3.73 & 7.49 \\
$\mathrm{TP} /(\mathrm{mg} / \mathrm{L})$ & $0.15 \sim 1.33$ & 0.95 & 0.09 \\
$\mathrm{NH}_{3}-\mathrm{N} /(\mathrm{mg} / \mathrm{L})$ & $0.35 \sim 1.69$ & 0.50 & 4.50 \\
$\mathrm{COD} /(\mathrm{mg} / \mathrm{L})$ & $2.04 \sim 5.76$ & 4.17 & 7.40 \\
$\mathrm{pH}$ & $7.03 \sim 9.23$ & 8.00 & 12.55 \\
\hline
\end{tabular}

环保绞吸式挖泥船是目前常采用的环保疏浚方法, 底泥在水下与水混合变成高含水率泥浆, 由此产生了带 有大量细小颗粒物, 富含有机质和氮磷营养盐等污染物 质的浑浊余水. 沙河水库疏浚原水中各种污染物浓度见 表 2 , 根据范铮等 ${ }^{[17]}$ 的研究, 河道清淤疏浚余水中 SS 浓 度为 $8 \sim 821 \mathrm{mg} / \mathrm{L}, \mathrm{COD}$ 为 $15 \sim 489 \mathrm{mg} / \mathrm{L}, \mathrm{NH}_{3}-\mathrm{N}$ 浓度为 $4.58 \sim 134 \mathrm{mg} / \mathrm{L}$, 与表 2 对比发现本文中沙河水库疏浚余 水污染物浓度普遍较低, 这与底泥的污染程度密切相 关, 河道清淤的对象一般为黑臭河道, 底泥及原水污染 都较为严重, 此外, 清淤工艺参数、泥水分离方法等因素 不同也会导致余水水质不同 ${ }^{[17,20]}$, 淤泥出水水质指标值 范围较广. 其他水体如泉州市山美水库 ${ }^{[8,14]}$ 经环保疏浚 后余水中 $\mathrm{SS}$ 浓度为 $1136 \mathrm{mg} / \mathrm{L}, \mathrm{TN}$ 浓度为 $6.9 \mathrm{mg} / \mathrm{L}, \mathrm{TP}$ 浓度为 $1.54 \mathrm{mg} / \mathrm{L}$, 滇池 ${ }^{[9]}$ 疏浚余水 $\mathrm{SS}$ 浓度为 $821 \mathrm{mg} /$

$\mathrm{L}, \mathrm{TN}$ 浓度为 $134 \mathrm{mg} / \mathrm{L}, \mathrm{TP}$ 浓度为 $0.98 \mathrm{mg} / \mathrm{L}, \mathrm{COD}$ 为 $489 \mathrm{mg} / \mathrm{L}$, 可以看出 $\mathrm{TP}$ 浓度在湖泊和水库疏浚余水 中差异不大, 而 SS、TN 和 COD 则表现出了显著的波动, 其中山美水库和沙河水库同为供水水源地, 优良的 上覆水水质和较轻的底泥污染程度使其疏浚余水中污染物浓度明显较低, 且二者余水中 TN TP 浓度也较为 相近.

高含水率泥浆经过浓缩后变成浓泥被泵人均化池, 为了提高过滤效率, 通常参考污泥脱水工艺掺加石 灰作为助滤剂 ${ }^{[21]}$. 沙河水库压滤尾水中各种污染物浓度见表 2 , 相对于疏浚原水, 由于板框压滤过程中滤布 的过滤性能, 出水浊度明显较低, 但石灰的掺人使得压滤尾水 $\mathrm{pH}$ 高达 12.55 , 呈现为强碱性. 尾水 $\mathrm{TP}$ 大约为 疏浚原水的 $1 / 10$, 由前文分析可知, TP 主要为颗粒态, 大部分最终沉降在了待压滤的底泥中, 而压滤出水中 磷浓度较低, 说明 TP 很好地吸附在了泥颗粒上, 不会随着间隙水的压滤或浸出而损失, 这与吴思麟等 ${ }^{[19]}$ 在 通济桥水库的研究中结论一致, 通济桥水库压滤尾水中 TP 浓度为 $0.11 \mathrm{mg} / \mathrm{L}$, 其疏浚原泥中 TP 浓度为 $363.36 \mathrm{mg} / \mathrm{kg}$, 与本文图 2 和表 3 对比发现, 原泥及尾水中 $\mathrm{TP}$ 浓度均相近. 而 $\mathrm{TN} 、 \mathrm{NH}_{3}-\mathrm{N}$ 和 COD 则有着明 显不同的趋势, 相对于疏浚原水, 压滤尾水中浓度明显升高, 说明在压滤过程中这些物质容易随着压滤尾水 被带出.

压滤尾水排人 $1^{\#}$ 池, 与疏浚原水混合成为该工艺需处理的余水, 虽然压滤尾水水量远低于疏浚原水水 量, 但由图 4 和图 7 可以看出, 其对氨氮和 $\mathrm{pH}$ 的影响是剧烈的, 造成后续氨氮浓度居高不下, 给氨氮的去除 增加了困难, 为了调节 $\mathrm{pH}$ 增设投酸设施, 提高了余水处理成本. 因此, 如何控制板框压滤的工艺参数或添加 某种助剂以降低尾水中氨氮浓度对于余水水质改善具有重要意义, 选择具有相同作用且经济合理的中性材 料代替石灰是未来的发展方向.

\section{2 处理后疏浚尾水水质排放标准}

目前我国还没有统一的疏浚尾水排放标准,在实际工程中,多数以余水中 SS 作为主要控制指标, 并参 照《污水综合排放标准》( GB 8978-1996) 一级和二级标准进行控制 ${ }^{[7-11]}$, 但就国内众多研究实例来看, 经过 普遍采用的物理化学方法处理后, SS 指标远优于一级标准 ${ }^{[8-9,11,14,22]}$, 因此笼统地将此标准应用于所有工程, 对排放水质要求偏低. 表 3 为沙河水库疏浚余水经过处理后的出水水质, 对比《污水综合排放标准》( GB 8978－1996) (以下简称污水标准)、《城镇污水处理厂污染物排放标准》( GB 18918－2002) (以下简称城镇 污水厂标准) 和《地表水环境质量标准》( GB 3838-2002) (以下简称地表水标准), 各指标均优于污水标准 
一级标准和城镇污水厂标准一级 A 标准,除 TN 和氨氮指标外,其他均可达到地表水 IV 类标准.

表 3 沙河水库排放出水水质

Tab.3 The discharge water quality of Shahe Reservoir

\begin{tabular}{|c|c|c|c|c|c|}
\hline 时间 & $\mathrm{TN} /(\mathrm{mg} / \mathrm{L})$ & $\mathrm{TP} /(\mathrm{mg} / \mathrm{L})$ & $\mathrm{NH}_{3}-\mathrm{N} /(\mathrm{mg} / \mathrm{L})$ & $\mathrm{COD}_{\mathrm{Mn}} /(\mathrm{mg} / \mathrm{L})$ & $\mathrm{pH}$ \\
\hline 11 月上旬 & 2.67 & 0.06 & 2.13 & 2.63 & 8.81 \\
\hline 11 月下旬 & 2.40 & 0.05 & 1.49 & 3.34 & 8.02 \\
\hline 12 月上旬 & 3.99 & 0.03 & 1.53 & 5.47 & 8.07 \\
\hline 12 月下旬 & 1.30 & 0.01 & 1.12 & 2.89 & 7.90 \\
\hline 1 月上旬 & 2.20 & 0.04 & 1.04 & 6.08 & 8.13 \\
\hline 1 月下旬 & 2.17 & 0.03 & 1.70 & 2.52 & 7.17 \\
\hline 污水标准 & & & 优于一级标准 & & \\
\hline 城镇污水厂标准 & & & 优于一级 A 标准 & & \\
\hline 地表水标准 & $\mathrm{IV} \sim$ 劣 $\mathrm{V}$ 类 & I $\sim$ IV类 & $\mathrm{IV}$ 劣 V类 & II $\sim$ IV类 & $6 \sim 9$ \\
\hline
\end{tabular}

霍守亮等 ${ }^{[7]}$ 和史云鹏等 ${ }^{[23]}$ 分别针对西五里湖和东钱湖疏浚堆场余水开展研究,均发现 SS 与 TN、TP、 COD 之间有显著的相关关系, 但与氨氮相关性较差, 本文也得到了类似的结论. 因此,通过控制疏浚余水 SS 基本可以控制余水水质,但无法保证出水氨氮指标, 此外, 对于不同的河湖水库, 底泥污染程度及上覆水水 质不同,仅仅通过控制 SS 也并不能都满足疏浚尾水的排放水质要求.

尾水排放首先应考虑目前常用处理工艺能达到的水质标准,在技术可行、经济合理的前提下根据受纳 水体的水质情况和水质目标进行优化. 对于城市黑臭河道, 清淤后河流生态系统的自净能力逐渐恢复, 河道 的疏浚余水净化后出水排人原河道时水质不必优于原水,可依靠河道本身自行改善, 如排人城镇污水管网, 则应满足《污水排人城镇下水道水质标准》( $\mathrm{GB} / \mathrm{T} 31962-2015$ ), 且须征得下游污水处理厂同意. 对于湖 泊、水库, 其疏浚尾水排人时应尽量消除对受纳水体生物的影响, 其次由于尾水中氨氮难以去除, 是否会引 起受纳水体的富营养化问题也应考虑, 如用于农田灌溉, 尾水还应满足《农田灌溉水质标准》( GB 50842021).

如上所述, 氨氮的去除在很多情况下可能会成为尾水达标排放的瓶颈, 而对于疏浚余水来说, 由于工程 上的工艺参数波动较大, 生物脱氮方法很难进行高效控制使其发挥作用, 相对而言, 物理化学脱氮方法更为 合适. 物理化学脱氮主要包括化学沉淀 (MAP) 法、折点加氯法、碱性吹脱法以及吸附法, 前 3 种因其运行成 本高, 且易造成二次污染, 因此很少使用. 吸附法是处理低浓度氨氮废水较有发展前景的方法之一, 目前关 于改性沸石对废水中氨氮吸附性能的研究较多, 室内实验表明改性沸石对于氨氮的吸附率可达 $90 \%$ 以上, 且相对浓度越低, 吸附效果越好 ${ }^{[24-25]}$; 焦巨龙等通过实验比较了沸石、麦饭石、硅藻土、膨润土和活性炭 5 种 材料对水中氨氮的吸附性能, 发现沸石的吸附量大并且解吸能力适中, 适合作为工程中的吸附脱氮材料 ${ }^{[26]}$. 因此,具体工程上可考虑将沸石吸附法用于低氨氮浓度疏浚余水的处理进行探索.

\section{4 结论}

1) 在环保疏浚过程中, 底泥中的磷比氮更易释放或吸附在细颗粒上, 从而随着疏浚过程进人余水中, 底 泥污染程度及原水水质是影响疏浚余水水质的重要因素.

2) 本工程采用“自然沉淀一混凝沉淀一生物曝气一表流湿地”工艺,经过该工艺的自然沉淀和混凝沉淀 单元后, 余水中大部分污染物可以去除, 后续的生物单元作用微乎其微, 氨氮是影响尾水水质的关键限制性 因素,降低其浓度可以从氨氮的吸附性去除方面探索.

3) 疏浚余水中 SS 与 TN、TP 等具有显著相关性, 随着 SS 去除 73\% 99\%, TN 可以去除 $21 \% \sim 72 \%$, TP 可以去除 69\% 96\%, 因此疏浚余水处理工艺以 SS 作为主要控制因子, 能够对 TN、TP 等污染物的去除效果 起到很好的指示性作用.

4)一般的环保疏浚工程只要进行合理的余水处理, 尾水大多数能够达到污水标准一级排放标准. 如果 受纳水体有更高的要求,氨氮的去除成为关键. 


\section{5 参考文献}

[ 1 ] Hu LW, Chen M, Yang Q et al. Present situation of heavy metal pollution in sediments and its remediation technologies. Environmental Engineering, 2017, 35(12) : 115-118,123. DOI: 10.13205/j.hjgc.201712023. [胡兰文, 陈明, 杨泉等. 底泥重金属污染现状及修复技术进展. 环境工程, 2017, 35(12) : 115-118,123.]

[ 2 ] Hu XZ, Jin XC, Lu SY, et al. Techniques for sediment pollution control and discussion on the applicability in lakes of China. Engineering Science, 2009, 11(9) : 28-33. [胡小贞, 金相灿, 卢少勇等. 湖泊底泥污染控制技术及其适用性 探讨. 中国工程科学, 2009, 11(9): 28-33.]

[ 3 ] Yan CZ, Fan CX, Yang JH et al. Prospect and progress of the study on environmental dredging technology of lake sediment. Environmental Pollution \& Control, 2004, 26(3): 189-192,243. [颜昌宙, 范成新, 杨建华等. 湖泊底泥环保疏 浚技术研究展望. 环境污染与防治, 2004, 26(3) : 189-192,243.]

[ 4 ] Zhong JC, Fan CX. Advance in the study on the effectiveness and environmental impact of sediment dredging. J Lake Sci, 2007, 19 (1) : 1-10. DOI: 10.18307/2007.0101. [ 钟继承, 范成新. 底泥疏浚效果及环境效应研究进展. 湖泊科学, $2007,19(1): 1-10$.

[ 5 ] Wang SC, Zhang CL, Huang YH et al. Study of diversification of water contents in dredged sediment storage yard. Rock and Soil Mechanics, 2010, 31(9) : 2823-2828. DOI: 10.16285/j.rsm.2010.09.002. [汪顺才, 张春雷, 黄英豪等. 堆场 疏浚淤泥含水率分布规律调查研究. 岩土力学, 2010, 31(9): 2823-2828.]

[ 6 ] Zhu W. Summary of the comprehensive discussion of the special committee on dredging and mud treatment and utilization of China water conservancy society. Water Resources Protection, 2018, 34(4): 93-94. [ 朱伟. 中国水利学会疏浚与泥处理 利用专委会综合讨论摘登. 水资源保护, 2018, 34(4): 93-94.]

[ 7 ] Huo SL, Jing YF, Xi BD et al. Full-scale experimental research on residual water treatment for environmental dredging. Research of Environmental Sciences, 2007, 20(1) : 75-79. DOI: 10.13198/j.res.2007.01.77.huoshl.014.[霍守亮, 荆一 凤, 席北斗等. 环保疏浚堆场余水处理生产性试验研究. 环境科学研究, 2007, 20(1): 75-79.]

[ 8 ] Yuan X, Mei XQ. Design and application of environmental protection dredging tail water treatment project. China Water Transport, 2017, 17 (7): 167-169, 184. [袁星, 梅晓庆. 环保疏浚尾水处理工程设计运用. 中国水运: 下半月, $2017,17(7): 167-169,184$.

[ 9 ] Liu ZG. Remaining water treatment technology in sediment dredging project. National Seminar on River Regulation and Ecological Restoration Technology, 2012. [刘志刚. 底泥疏浚工程中余水处理技术. 全国河道治理与生态修复技术交流 研讨会, 2012.]

[10] Wang Q, Li ZH. Study on treatment device and method to residual water at environmental dredging sediment storage area. Journal of Water Resources and Water Engineering, 2012, 23(2): 179-181. [王琦, 李中华. 环保疏浚底泥堆场余水处 理方法及实施装置研究. 水资源与水工程学报, 2012, 23(2)：179-181.]

[11] Zhang ZF, Wang Q, Li ZH. Design and application of ecological dredging waste water treatment projects for inland rivers and lakes. Water Resources Development Management, 2013, 33(2) : 9-10. [张志芳, 王琦, 李中华. 内陆河湖生态疏浚 余水处理工程设计运用. 水利建设与管理, 2013, 33(2): 9-10.]

[12] He PJ, Bian CL, Gu GW et al. Decontamination process for centrate of contaminated dredged sediments. Journal of Tongji University: Natural Science, 2002, 30(7):881-885. [何品晶, 市成林, 顾国维等. 受污染河道疏浚泥浆离心脱水上 清液净化工艺. 同济大学学报: 自然科学版, 2002, 30(7) : 881-885.]

[13] Lei Y. Discussion on the treatment method and implementation device for the residual water of environmental protection dredged sediment yard. Green Environmental Protection Building Materials, 2018, 134(4): 68. [雷雨. 关于环保疏浚底 泥堆场余水处理方法及实施装置的探讨. 绿色环保建材, 2018, 134(4) : 68.]

[14] Chen J, Chen L. Key construction technology for treatment of sediment dewatering consolidation tail water in environmental dredging. China Water \& Wastewater, 2019, 35(2) : 105-108. DOI: 10.19853/j.zgjsps.1000-4602.2019.02.022. [陈洁, 陈林. 疏浚底泥脱水工程排放尾水处理的关键技术. 中国给水排水, 2019, 35(2): 105-108.]

[15] Ministry of Environmental Protection of the People's Republic of China, Editorial Board of water and wastewater monitoring and analysis methods eds. Water and wastewater monitoring and analysis methods: 4th edition. Beijing: China Environmental Science Press, 2002: 243-372. [ 国家环境保护总局《水和废水监测分析方法》编委会. 水和废水监测分析方法: 
第 4 版. 北京: 中国环境科学出版社, 2002: 243-372.]

[16] American Society for Testing and Material. Standard test methods for moisture, ash, and organic matter of peat and other organic soils. 2000. http://www.astm.org/Standards/D2974.htm.

[17] Fan Z, Li XY. Discussion on the treatment method of environmental dredging and water treatment in river. China Water Conservancy Society, Peking University, 2015. [范铮, 粟晓燕. 河道环保疏浚余水处理方法探讨. 中国水利学会, 北 京大学, 2015.]

[18] Si J, Xing Y, Lu SY et al. Release rule research of submerged plants with temperature impact in contabescence. Chinese Agricultural Science Bulletin, 2009, 25(1): 217-223. [司静, 邢奕, 卢少勇等. 沉水植物衰亡过程中氮磷释放规律及 温度影响的研究. 中国农学通报, 2009, 25(1): 217-223.]

[19] Wu SL, Zhu W, Liu JM et al. Change laws of mud property and problems in typical environmental dredging treatment projects. Chinese Journal of Geotechnical Engineering, 2019, 41(12): 2290-2296. [ 吴思麟, 朱伟, 刘既明等. 环保疏浚泥 处理工程泥性质变化规律及问题分析. 岩土工程学报, 2019, 41(12): 2290-2296.]

[20] Li XF, Huang JY. Dredging dehydration technology and engineering application process. Port \& Waterway Engineering,

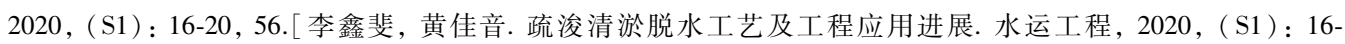
$20,56$.

[21] Yu ZR, Yu YC, Gao TY et al. The application and mechanism of lime in sludge conditioning. China Water \& Wastewater, 1989, 5(6) : 7-11, 2. DOI: 10.19853/j.zgjsps.1000-4602.1989.06.003. [余志荣, 郁雨苍, 高廷耀等. 石灰在污泥调 治中的应用及作用机理研究. 中国给水排水, 1989, 5(6): 7-11, 2.]

[22] Liu XQ, Qin J. Design and engineering application of environmental dredging scheme for large deep water reservoir. China Harbour Engineering, 2018, 38(12) : 31-36. DOI: 10.7640/zggwjs201812007. [刘小强, 秦俊. 大型深水水库环保疏 浚方案设计及工程应用. 中国港湾建设, 2018, 38(12): 31-36.]

[23] Shi YP, Cao H, Wang DD. Study on the correlation of pollutant concentrations in the residual water of Dongqian Lake sediment dredging. China Rural Water and Hydropower, 2013, (12) : 30-33. [史云鹏, 曹卉, 汪冬冬. 东钱湖底泥疏浚余 水中污染物浓度的相关性研究. 中国农村水利水电, 2013, (12) : 30-33.]

[24] Lu XG, Pan XH, Zheng YJ. Study on adsorption performance of modified and natural zeolite on ammonia nitrogen in water. Ion Exchange and Adsorption, 2020, 36(6) : 520-529. [鲁秀国, 盘贤豪, 郑宇佳. 改性及天然沸石对水中氨氮吸附 性能的研究. 离子交换与吸附, 2020, 36(6): 520-529.]

[25] Cao L, Zhang L, Zhang XH et al. Study on performance of new composite materials for nitrogen and phosphorus removal in wastewater treatment. Acta Scientiae Circumstantiae, 2020, 40(11) : 3950-3957. DOI: 10.13671/j.hjkxxb.2020.0171. [曹蕾, 张龙, 张效华等. 新型复合材料处理氮磷废水的性能研究. 环境科学学报, 2020, 40(11): 3950-3957.]

[26] Jiao JL, Yang SW, Xie Y et al. Adsorption properties of ammonia nitrogen in aqueous solution by various materials. Environmental Science, 2019, 40(8) : 3633-3641. DOI: 10.13227/j.hjkx.201811199. [焦巨龙, 杨苏文, 谢宇等. 多种材料 对水中氨氮的吸附特性. 环境科学, 2019, 40(8):3633-3641.] 